\title{
Effect of Europium(III) Chloride on the Aggregation Behavior of Sodium Dodecyl Sulfate
}

\author{
A. J. M. Valente,* H. D. Burrows, R. F. Pereira, A. C. F. Ribeiro, \\ J. L. G. Costa Pereira, and V. M. M. Lobo \\ Department of Chemistry, University of Coimbra, 3004-535 Coimbra, Portugal
}

Received January 30, 2006. In Final Form: April 24, 2006

\begin{abstract}
The effect of $\mathrm{EuCl}_{3}$ on the aggregation processes of sodium dodecyl sulfate was investigated. Electrical conductivity data, combined with $\mathrm{Eu}(\mathrm{III})$ luminescence measurements, suggest that the formation of micelles involving $\mathrm{EuCl}_{3}$ and SDS occurs at low SDS concentration; the formation of these mixed aggregates was also monitored by light scattering, which indicates that the addition of $\mathrm{EuCl}_{3}$ to SDS concentration at values below the critical micelle concentration of the pure surfactant results in a much higher light scattering than that found just with SDS micelles. It was also found that the $\mathrm{Eu}(\mathrm{III}) / \mathrm{DS}^{-}$complexes are formed with a binding ratio which varies between 20 and 4, depending on the initial concentration of Eu(III). As the concentration increases, turbidity occurs initially, but solutions become clear subsequently. In contrast to the behavior of SDS in the presence of aluminum(III), no flocculation was observed. From the analysis of electrical conductivity data and comparison with other systems, it is suggested that growth of aggregates happens, probably with formation of nonspherical systems. At the highest concentrations these may involve just Eu(III) and $\mathrm{DS}^{-}$ions. The effect of temperature on the SDS micellization process was studied. The calculated free energy of SDS micellization is not dependent on the initial $\mathrm{EuCl}_{3}$ but is dependent on the final balance between the presence of counterions in solution (ionic strength) and the temperature.
\end{abstract}

\section{Introduction}

The aggregation of ionic surfactants in aqueous solution is influenced by the presence of electrolytes. The addition of an electrolyte will, in general, tend to induce the formation of aggregates at concentrations below the critical micelle concentration (cmc) of the pure surfactant, ${ }^{1}$ while with many electrolytes, specific interactions between the surfactant ion and electrolyte counterion will lead to a reduction in solubility ${ }^{2}$ and an increase in the Krafft temperature. ${ }^{3}$ The cmc, aggregation number, and shape are also dependent on the electrolyte, counterion valence, polarizability, and size..$^{4-8}$ Normally, divalent or higher valent counterions are believed to lead to lower cmc values than the corresponding surfactant with monovalent counterions. ${ }^{4-8}$

The study of interactions of ions of high valency with ionic surfactants is of practical importance in areas such as detergency (interactions and precipitation of ionic surfactants by multivalent counterions restrict the utilization of ionic surfactants in hard water) and recovery of surfactants from surfactant-based separation processes..$^{8,9-12}$ In addition, there is currently considerable interest in using ionic surfactants as templates for the preparation

* To whom correspondence should be addressed. Phone: +351 239854459. Fax: +351 239 827703. E-mail: avalente@ci.uc.pt.

(1) Holmberg, K.; Jönsson, B.; Kronberg, B.; Lindman, B. Surfactants and Polymers in Aqueous Solution, 2nd ed.; Wiley: Chichester, U.K., 2003.

(2) Miyamato, S. Bull. Chem. Soc. Jpn. 1960, 33, 371-375.

(3) Hato, M.; Shinoda, K. J. Phys. Chem. 1973, 77, 378-381.

(4) Tanford, C. The hydrophobic effect: Formation of Micelles and Biological Membranes; Wiley: New York, 1980; p 60.

(5) Satake, I.; Iwamatsu, I.; Hosokawa, S.; Matuura, R. Bull. Chem. Soc. Jpn.

1963, 36, 204-209.

(6) Hato, M.; Shinoda, K. Bull. Chem. Soc. Jpn. 1973, 46, 3889-3890.

(7) Moroi, Y.; Matuura, R.; Tanaka, M.; Murata, Y.; Aikawa, Y.; Furutani, E.; Kuwamura, T. J. Phys. Chem. 1990, 94, 842.

(8) Vasilescu, M.; Angelescu, D.; Caldararu, H.; Almgren, M.; Khan, A. Colloids Surf., A 2004, 235, 57-64.

(9) Somasundaram, P.; Ananthpadmanabhan, K. P.; Celik, M. S. Langmuir 1988, 4, 1061

(10) Chou, S. I.; Bae, J. H. J. Colloid Interface Sci. 1983, 96, 193-203.

(11) Talens, F. I.; Patón, P.; Gaya, S. Langmuir 1998, 14, 5046-5050. 6064

(12) Paton-Morales, P.; Talens-Alesson, F. I. Langmuir 2001, 17, 6059- of mesosopic or mesoporous materials,${ }^{13}$ and the potential of the aluminum(III)/sodium dodecyl sulfate system in this area has been studied. ${ }^{8}$ Of particular importance for aggregation in this system is the enhanced interaction between the high valent cation and anionic surfactant.

We have particular interest in the behavior of trivalent lanthanide ions, since they have attractive spectroscopic and magnetic properties. ${ }^{14}$ Lanthanides have been used extensively as luminescent probes in the investigation of metal-binding sites in biological materials $s^{15,16}$ as well as in the study of surfactant association in solution. ${ }^{17,18}$ In addition, systems of SDS micelles with lanthanide ions have been used for studying magnetic field effects on geminate pair recombination of radicals, ${ }^{19}$ or photoinduced emulsion polymerization, ${ }^{20}$ and are also of increasing interest in relation to the mesomorphism of lanthanide salts of anionic amphiphiles for materials applications..$^{21,22}$ Lanthanides incorporated in suitable mesoporous materials are also important for catalysis. ${ }^{23}$

In a previous publication, ${ }^{24}$ a luminescence, EPR, and Monte Carlo simulation study of the association of lanthanide cations

(13) Monnier, A.; Schuth, F.; Huo, Q.; Kumar, D.; Margolese, D.; Maxwell, R. S.; Stucky, G. D.; Krishnamurthy, M.; Petroff, P.; Firouzi, A.; Jamicke, M.; Chmelka, B. F. Science 1993, 261, 1299-1303.

(14) Lanthanide Probes in Life, Chemical and Earth Sciences: Theory and Practice; Bünzli, J. C. G., Choppin, G. R., Eds.; Elsevier: Amsterdam, 1989.

(15) Williams, R. J. P. Struct. Bonding 1982, 50, 79-119.

(16) Bünzli, J. C. G.; Choppin, G. R. Lanthanides Probes in Life, Chemical and Earth Sciences; Elsevier: Amsterdam, 1989; Chapters 6 and 7.

(17) Miguel, M. G.; Burrows, H. D.; Formosinho, S. J.; Lindman, B. J. Mol. Struct. 2001, 563-564, 89-98.

(18) Almgren, M. Adv. Colloid Interface Sci. 1992, 41, 9-32.

(19) Turro, N. J.; Lei, X.; Gould, I. R.; Zimmt, M. B. Chem. Phys. Lett. 1985 $120,397-400$

(20) Turro, N. J.; Arora, K. S. Macromolecules 1986, 19, 42-46.

(21) Marques, E. F.; Burrows, H. D.; Miguel, M. G. J. Chem. Soc., Faraday Trans. 1998, 94, 1729-1736.

(22) Binnemans, K.; Jongen, L.; Gorller-Walrand, C.; D’Olieslager, W.; Hinz, D.; Meyer, G. Eur. J. Inorg. Chem. 2000, 1429-1436.

(23) Berry, F. J.; Carbucicchio, M.; Chiari, A.; Johnson, C.; Moore, E. A. Mortimer, M.; Vetel, F. F. F. J. Mater. Chem. 2000, 10, 2131-2136.

(24) Tapia, M. J.; Burrows, H. D.; Azenha, M. E. D. G.; Miguel, M. G.; Pais, A. A. C. C.; Sarraguça, J. M. G. J. Phys. Chem. B 2002, 106, 6966-6972. 
with sodium dodecyl sulfate micelles was reported. It was found by various techniques that the trivalent lanthanide ions ( $\mathrm{Tb}(\mathrm{III})$, $\mathrm{Eu}(\mathrm{III}), \mathrm{Ce}(\mathrm{III})$, and Gd(III)) bind to SDS micelles predominantly by electrostatic interactions and that there is no covalent bond between them. In addition, on binding the cation one hydration water molecule was lost. In the present paper, we describe the effect of $\mathrm{Eu}(\mathrm{III})$ on the structural properties of SDS over a wide concentration range around the $\mathrm{cmc}$ as seen by electrical conductivity measurements. This is complemented by results from luminescence and static light scattering. Particular attention is given to association processes which occur below the $\mathrm{cmc}$ of pure SDS ([SDS] < cmc). The effect of temperature on the $\mathrm{Eu}(\mathrm{III}) / \mathrm{SDS}$ interactions is also analyzed.

\section{Experimental Procedure}

2.1. Materials. Europium chloride(III) hexahydrate $(99.9 \%$, Aldrich) and sodium dodecyl sulfate, SDS (Merck-pro analysis), were used as received. All solutions were prepared using Millipore-Q water. No control was made on the $\mathrm{pH}$, which was that naturally occurring in each solution (see Results and Discussion section).

2.2. Conductance Measurements. Solution electrical resistances were measured with a Wayne-Kerr model 4265 automatic LCR meter at $1 \mathrm{kHz}$. A Shedlovsky-type conductance cell was used and had a cell constant around $0.8465 \mathrm{~cm}^{-1} .{ }^{25}$ Cell constants were measured using the procedure described elsewhere. ${ }^{26}$ Measurements were taken at $25.00,30.00$, and $40.00( \pm 0.01){ }^{\circ} \mathrm{C}$ using a Grant thermostat bath. Solutions were always used within $24 \mathrm{~h}$ of preparation. In a typical experiment, $100 \mathrm{~mL}$ of $\mathrm{EuCl}_{3}$ solution was placed in the conductivity cell; then, aliquots of sodium dodecyl sulfate were added using a Methrom 765 dosimate micropipet. To maintain the constant concentration of $\mathrm{Eu}(\mathrm{III})$, the solvent used in the preparation of SDS solution was the same $\mathrm{EuCl}_{3}$ solution placed in the conductivity cell. The conductance of the solution was measured after each addition and corresponds to the average of three ionic conductances, calculated from experimental data using homemade software.

2.3. Fluorescence Technique. For luminescence spectral measurements, a Spex Fluorog 111 spectrofluorimeter was used in a right-angle configuration with excitation at $393 \mathrm{~nm}$, with $2.5 \mathrm{~nm}$ excitation bandwidth and $1.25 \mathrm{~nm}$ emission bandwidth.

Static light scattering measurements were carried out using a Spex 111 spectrofluorimeter in $90^{\circ}$ configuration with the excitation monocromator set at $430 \mathrm{~nm}$, and the emission spectrum scanned between 410 and $450 \mathrm{~nm}$, following the indications of Mougán et al. ${ }^{27}$ Excitation and emission slits of $1.25 \mathrm{~nm}$ were used.

2.4. pH Measurements. $\mathrm{pH}$ measurements were carried out with a Radiometer PHM $240 \mathrm{pH}$ meter with an Ingold U457-K7 pH conjugated electrode; the $\mathrm{pH}$ was measured on fresh solutions, and the electrode was calibrated immediately before each experimental set of solutions using IUPAC-recommended $\mathrm{pH} 4$ and 7 buffers. From $\mathrm{pH}$ meter calibration, a zero $\mathrm{pH}$ of $6.65( \pm 0.04)$ and sensitivity of $99.1 \%$ were obtained.

\section{Results and Discussion}

The effect of $\mathrm{EuCl}_{3}\left(8 \times 10^{-6}\right.$ to $\left.6 \times 10^{-4} \mathrm{M}\right)$ on the electrical conductivity of sodium dodecyl sulfate, at three different temperatures $\left(25,30\right.$, and $\left.40^{\circ} \mathrm{C}\right)$, was analyzed. At all temperatures, the specific conductance of $\mathrm{SDS} / \mathrm{EuCl}_{3}$ solutions versus [SDS] shows a similar trend. At Eu(III) concentrations below $6 \times 10^{-5}$ $\mathrm{M}$, the electrical conductance of $\mathrm{SDS} / \mathrm{EuCl}_{3}$ solutions upon addition of SDS is similar to that of pure SDS in aqueous solutions

(25) Ribeiro, A. C. F.; Valente, A. J. M.; Lobo, V. M. M.; Azevedo, E. F. G.; Amado, A. M.; Costa, A. M. A.; Ramos, M. L.; Burrows, H. D. J. Mol. Struct. 2004, 703, 93-101.

(26) Barthel, J.; Feuerlin, F.; Neuder, R.; Wachter, R. J. Solution Chem. 1980, 9, 209-219.

(27) Mougán, M. A.; Coello, A.; Jover, A.; Meijide, F.; Tato, J. V. J. Chem. Educ. 1995, 72, 284-286.

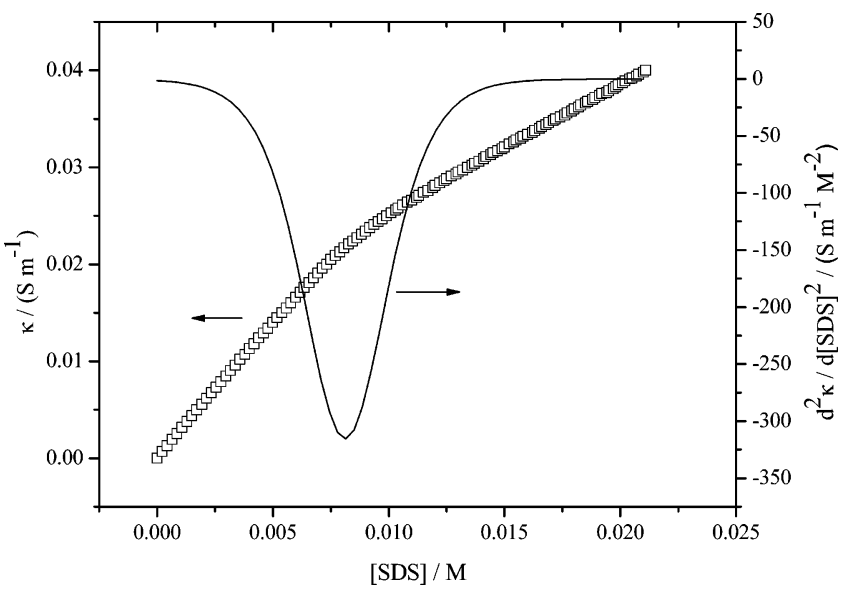

Figure 1. Representative plot of specific electrical conductance, $k$, versus SDS concentration (data points), at $298.15 \mathrm{~K}$, and the corresponding second derivative (line) used in calculation of the critical micelle concentration.

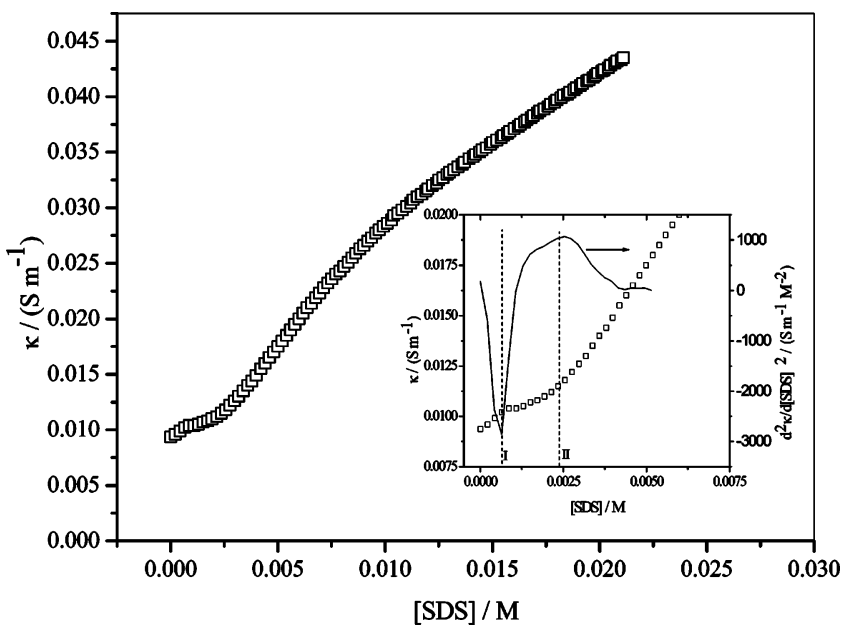

Figure 2. Specific conductance of sodium dodecyl sulfate (SDS) in $0.6 \mathrm{mM} \mathrm{EuCl}_{3}$ solution, at $25^{\circ} \mathrm{C}$, as a function of molar SDS concentration. Inset: deviations from linearity observed at very low SDS concentrations (data points) and their corresponding second derivative (line). For further explanations see text.

(e.g., Figure 1$){ }^{28}$ however, different behavior is observed at higher Eu(III) concentrations $\left(>6 \times 10^{-5} \mathrm{M}\right)$, with a loss in the linearity in the plots at low SDS concentrations (see inset, Figure 2). Before discussing possible causes for this, to test the validity of our methods, the critical micelle concentration of SDS in aqueous solutions at different temperatures was calculated using the second derivative of the specific conductance as a function of SDS concentration, as described elsewhere ${ }^{29}$ and as schematically presented in Figure 1. Using this procedure, the values of the $\mathrm{cmc}$ of SDS at 25,30 and $40{ }^{\circ} \mathrm{C}$ are $8.34( \pm 0.03), 8.47$ $( \pm 0.04)$ and $8.81( \pm 0.03) \mathrm{mM}$, respectively. Within experimental error, these values are identical to those reported in the literature for this temperature range $(8.39,8.44$, and $8.88 \mathrm{mM}$, respectively). ${ }^{30}$

In the presence of $\mathrm{EuCl}_{3}$, the apparent critical micelle concentration, $\mathrm{cmc}^{\mathrm{ap}}$, of SDS was calculated using this same method. Figure 3 shows the effect of $\mathrm{Eu}$ (III) concentration and temperature on SDS $\mathrm{cmc}^{\mathrm{ap}}$. It is known that, in general, the

(28) Dutkiewicz, E.; Jakubowska, A. Colloid Polym. Sci. 2002, 280, 10091014.

(29) Carpena, P.; Aguiar, J.; Bernaola-Galván, P.; Carnero Ruiz, C. Langmuir 2002, 18, 6054-6058.

(30) Mukerjee, P.; Mysels, K. J. In Critical Micelle Concentration of Aqueous Surfactant Systems; National Bureau of Standards: Washington, DC, 1971. 


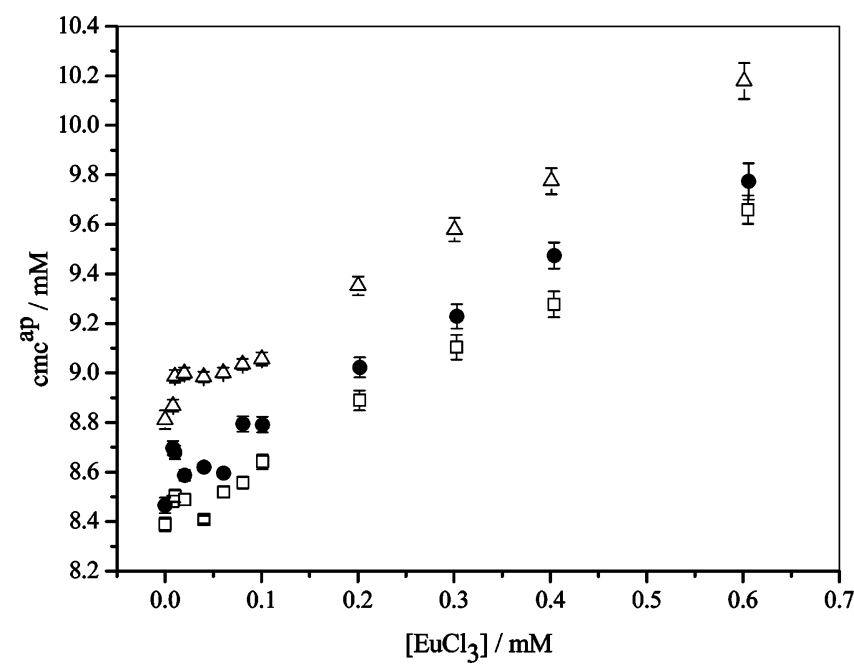

Figure 3. Effect of added $\mathrm{EuCl}_{3}$ on the apparent critical micelle concentration ( $\mathrm{cmc}^{\text {ap }}$ ) of SDS at different temperatures: $(\square) 298.15$ $\mathrm{K},(\bullet) 303.15 \mathrm{~K}$, and $(\triangle) 313.15 \mathrm{~K}$.

presence of nonassociated electrolytes ${ }^{1}$ and some metal complexes $^{31}$ will induce the formation of SDS micelles. This may be due either to the effect of ionic strength on the aggregation phenomena of the surfactant ${ }^{32}$ or, in the case of higher valent counterions, to a decrease in the $\mathrm{cmc}$ due to formation of the corresponding micelles of the surfactants of these ions formed by counterion exchange. ${ }^{5-8}$ It has been reported from both experimental measurements and simulation studies that lanthanide ions show a strong tendency to associate electrostatically with SDS micelles. ${ }^{24}$ Also, although no value was given, the $\mathrm{cmc}$ of lanthanum(III) dodecyl sulfate is suggested to be considerable lower than that of SDS. ${ }^{33}$ In the present system, aggregates in this concentration region are likely to have both sodium and europium counterions. In fact, there appears to be a linear relationship, independent of temperature, of the $\mathrm{cmc}^{\text {ap }}$ as a function of Eu(III) concentration, with a slope of $2.14( \pm 0.08)$. These changes are accompanied by the onset of turbidity. However, in contrast to what is seen with sodium dodecyl sulfate in the presence of aluminum(III) ${ }^{11,12}$ or DNA in the presence of trivalent lanthanide ions, ${ }^{34}$ no precipitation is seen, and at higher concentrations the solutions become clear.

The analysis of the specific electrical conductance in the region below the cmc of pure SDS (Figure 2, inset), coupled with a comparison of the behavior with that of SDS in the presence of aluminum(III), ${ }^{8,11,12}$ suggests possible interpretations for the interaction mechanism between $\mathrm{EuCl}_{3}$ and SDS. From the inset to Figure 2, we can distinguish three regions with different slopes. Initially, the addition of SDS leads to an increase in the electrical conductance of the $\mathrm{SDS} / \mathrm{EuCl}_{3}$ mixture until an SDS critical aggregation concentration $\left(\mathrm{cac}_{1}\right)$ is reached, line I in Figure 2. This corresponds to the region of onset of flocculation reported in systems involving SDS and the trivalent $\mathrm{Al}(\mathrm{III})$ ion, ${ }^{11,12}$ and we believe it to be due to formation of mixed sodium and europium(III) dodecyl sulfate micelles. After this point, further increase in SDS concentration leads to a smaller slope of $\kappa=$ $f([\mathrm{SDS}])$ until a maximum interaction concentration (mic) is reached, line II in Figure 2. Under these conditions, mixed

(31) Pagliero, D.; Arguello, G. A.; Gsponer, H. E. J. Colloid Interface Sci. 1999, 215, 16-22.

(32) Almgren, M.; Gimel, J. C.; Wang, Ke.; Karlsson, G.; Edwards, K.; Brown, W.; Mortensen, K. J. Coll. Interface Sci. 1998, 202, 222-231.

(33) Bo<crn>zić, J.; Krznarić, I.; Kallay, N. Colloid Polym. Sci. 1979, 257, $201-205$.

(34) Costa, D.; Burrows, H, D.; Miguel, M. da G. Langmuir 2005, 21, 1049210496

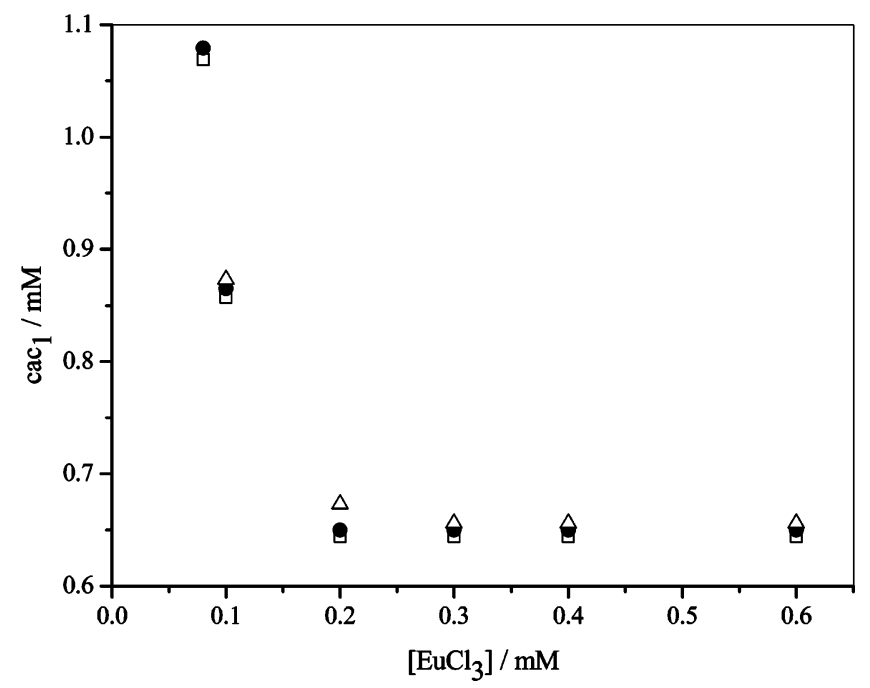

Figure 4. Effect of $\mathrm{EuCl}_{3}$ concentration on the $\mathrm{cac}_{1}$ of SDS/EuCl 3 aggregates at different temperatures: ( $\square$ ) $298.15 \mathrm{~K}$, (•) $303.15 \mathrm{~K}$, and $(\triangle) 313.15 \mathrm{~K}$. The error bars are inside the data points.

aggregate formation will occur, and consequently, the increase of electrical conductivity is not so significant (the size of aggregate ionic species increases and the observed increase in the specific conductance can be due to a release of counterions); finally, at [SDS] $>$ mic, the shape of the plot of electrical conductance as a function of [SDS] concentration, in the presence of aqueous solutions of $\mathrm{EuCl}_{3}$, is similar to that found in pure aqueous solutions. Under these conditions, no more $\mathrm{Eu}(\mathrm{III})$ is available to induce $\mathrm{Eu}(\mathrm{III}) / \mathrm{DS}^{-}$aggregate formation and/or the maximum aggregation number is reached, and after this, SDS will be in excess, such that the solution behaves in a similar way to pure SDS in aqueous solution.

Figure 4 shows the effect of $\mathrm{EuCl}_{3}$ concentration in the $\mathrm{cac}_{1}$. The $\mathrm{cac}_{1}$ decreases when $\left[\mathrm{EuCl}_{3}\right]$ increases and reaches a constant value at $\left[\mathrm{EuCl}_{3}\right] \geq 0.2 \mathrm{mM}$. This plateau is independent of temperature, within the experimental error (around 1\%); that is, $\mathrm{cac}_{1}=0.64,0.65$, and $0.66 \mathrm{mM}$ to 25,30 , and $40^{\circ} \mathrm{C}$, respectively. This can be contrasted with the rather complex effect of temperature on the micellization of a series of dodecyl sulfates of divalent metal ions. ${ }^{35}$ These results suggest that $\mathrm{EuCl}_{3}$ plays an important role in the formation of aggregates working as a limiting reactant in such aggregates, and supporting the idea that the plateau value of $\operatorname{cac}_{1}(0.65 \pm 0.1 \mathrm{mM})$ corresponds to the cmc of europium(III) dodecyl sulfate. Although we have been unable to find any literature values for comparison, this value seems very reasonable, since it is intermediate between the lower limit of the value for lanthanum(III) dodecyl sulfate $(\mathrm{cmc} \geq 0.22$ $\mathrm{mM})^{33}$ and those of the dodecyl sulfates of the divalent ions $\mathrm{Ca}^{2+}, \mathrm{Mg}^{2+}, \mathrm{Pb}^{2+}, \mathrm{Cd}^{2+}$, and $\mathrm{Zn}^{2+}$ ( $\mathrm{cmc}$ values in the range $1.0-1.8 \mathrm{mM}){ }^{36}$

Further support for formation of $\mathrm{SDS} / \mathrm{EuCl}_{3}$ aggregates at low (below the cmc of pure surfactant) SDS concentrations comes from static light scattering and fluorescence measurements. Upon addition of europium(III) chloride to a $7 \mathrm{mM}$ SDS solution, there is a dramatic increase in scattering intensity between 0.01 and $0.6 \mathrm{mM}$ europium(III), consistent with the formation of micelles (Figure 5). The light scattering in this case is significantly higher than that found when adding of $\mathrm{EuCl}_{3}$ to a $11 \mathrm{mM}$ SDS solution, where both SDS and europium/sodium dodecyl sulfate micelles are expected to be formed. This seems

(35) Sowada, R. Phys. Chem. 1986, 267, 915-920.

(36) Miyamoto, S. Bull. Chem. Soc. Jpn. 1960, 33, 375-379. 


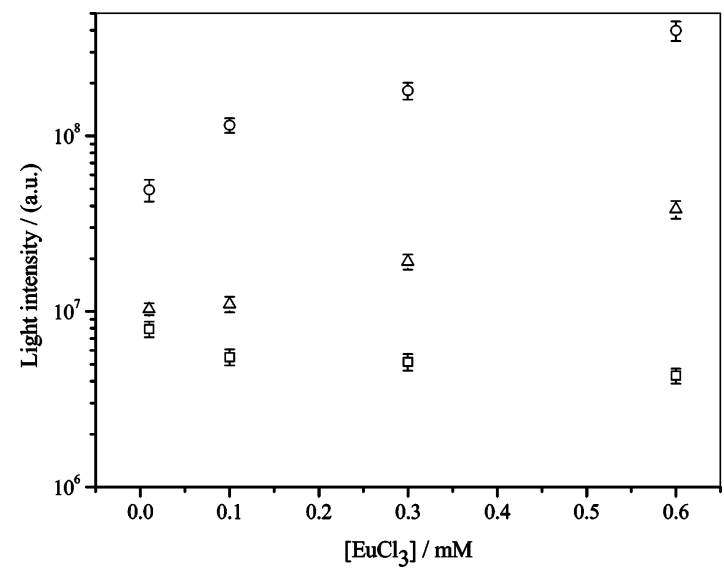

Figure 5. Gradual increase of light scattering upon addition of Eu(III) to different SDS aqueous solutions: ( $\square$ ) $0 \mathrm{mM}$, (O) 7.03 $\mathrm{mM},(\triangle) 11.6 \mathrm{mM}$.

reasonable, since it is known from both fluorescence quenching studies $^{37}$ and EPR spin probe measurements ${ }^{38}$ that micelle size is greater in the presence of higher valent ions than in pure SDS.

Lanthanide ions present well-defined luminescence resulting from $\mathrm{f}-\mathrm{f}$ transitions. This may give information on both the coordination environment and the degree of hydration of these ions. ${ }^{39}$ However, the $\mathrm{f}-\mathrm{f}$ transitions of ions such as Eu(III) are generally forbidden by both spin and Laporte selection rules and, hence, have very low molar absorption coefficients. ${ }^{40}$ This explains the very low fluorescence emission at $424 \mathrm{~nm}$ in the absence of SDS. In the presence of SDS, the emission of fluorescence clearly increases (Figure 6). Such behavior may be explained both by a decrease in the number of coordinated water molecules and by binding of Eu(III) to species of different charges, such as $\mathrm{DS}^{-}$, by forming new $\mathrm{Eu}(\mathrm{III}) / \mathrm{DS}^{-}$aggregates. ${ }^{24}$ The results are fully consistent with the model of formation of $\mathrm{Eu}(\mathrm{III}) / \mathrm{Na}^{+}$dodecyl sulfate micelles below the cmc of pure SDS .

The possible effect of $\mathrm{EuCl}_{3}$ hydrolysis ${ }^{41}$ on the SDS $\mathrm{cmc}^{\text {ap }}$ was studied. A decrease in the $\mathrm{pH}$ of the solution will tend to decrease the SDS association ${ }^{42,43}$ and, consequently, will contribute to a $\mathrm{cmc}^{\text {ap }}>\mathrm{cmc}$. Figure 7 shows that the hydrolysis of $\mathrm{EuCl}_{3}$ leads to a decrease in $\mathrm{pH}$ from around 5.8 (pure water) to around 5.0; such a decrease corresponds to an increase of hydrogen ion concentration of about $8 \mu \mathrm{M}$. However, in the $\mathrm{Eu}(\mathrm{III}) / \mathrm{SDS}$ solutions a buffer-type effect occurs, which can be attributed to the SDS. ${ }^{44}$ Under these circumstances (in the presence of SDS), the increase of hydrogen ion concentration is just 0.4 and $0.1 \mu \mathrm{M}$ below and above the SDS cmc, respectively. This very low $\mathrm{pH}$ change cannot be responsible for the observed SDS $\mathrm{cmc}^{\text {ap }}$ behavior.

A further question is if there is the formation of $\mathrm{DS}^{-} / \mathrm{Eu}(\mathrm{III})$ aggregates, can we estimate the binding ratio between them?

Table 1 shows the values of the maximum interaction concentration (mic) for $\mathrm{EuCl}_{3} / \mathrm{SDS}$ aqueous mixtures, with $\left[\mathrm{EuCl}_{3}\right]>0.06 \mathrm{mM}$. Following these values, it is possible to calculate the binding ratio $\left(\beta=\mathrm{mic} /\left[\mathrm{EuCl}_{3}\right]\right)$, which gives us an

(37) Almgren, M.; Swarup, S. J. Phys. Chem. 1983, 87, 876-881.

(38) Bales, B. L.; Stenland, C. J. Phys. Chem. 1993, 97, 3418-3433.

(39) Frey, S. T.; Horrocks, W. D., Jr. Inorg. Chim. Acta 1995, 229, 383-390.

(40) Tapia, M. J.; Burrows, H. D. Langmuir 2002, 18, 1872-1876.

(41) Baes, C. F., Jr.; Mesmer, R. E. The Hydrolysis of Cations; John Wiley and Sons: New York, 1976.

(42) Valente, A. J. M.; Burrows, H. D.; Polishchuk, A. Ya.; Miguel, M. G.;

Lobo, V. M. M. Eur. Polym. J. 2004, 40, 109-117.

(43) Cistola, D. P.; Hamilton, J. A.; Small, D. M. Biochemistry 1988, 27, $1881-1888$.

(44) Bunton, C. A.; Ohmenzetter, K.; Sepulveda, L. J. Phys. Chem. 1977, 81, 2000-2004.
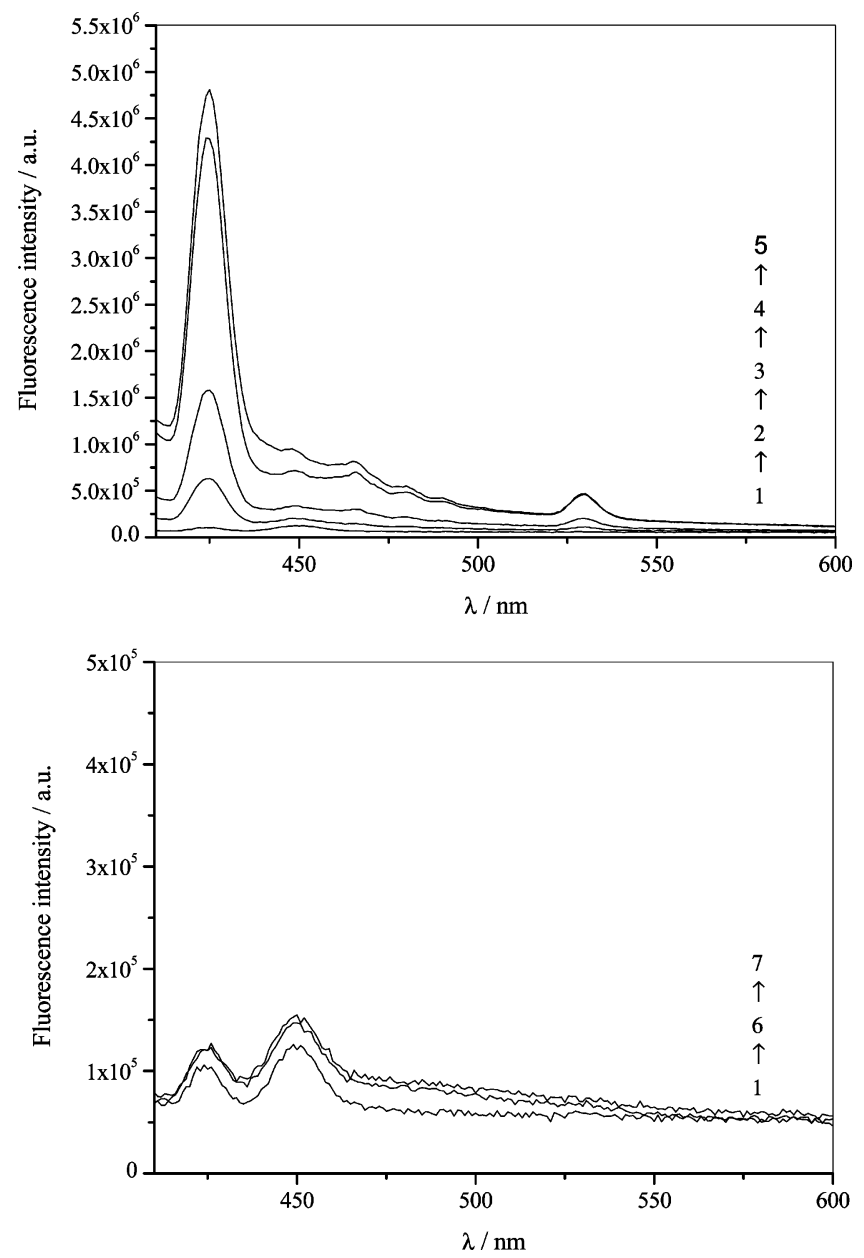

Figure 6. Emission spectra of $0.5 \mathrm{mM} \mathrm{Eu(III)} \mathrm{with} \mathrm{additions} \mathrm{of}$ different SDS concentrations at $25^{\circ} \mathrm{C}$ : (1) $[\mathrm{SDS}]=0 \mathrm{M}$; (2) [SDS] $=1 \mathrm{mM}$; (3) $[\mathrm{SDS}]=3 \mathrm{mM}$; (4) $[\mathrm{SDS}]=5 \mathrm{mM}$; (5) $[\mathrm{SDS}]=7$ $\mathrm{mM} ;(6)[\mathrm{SDS}]=9 \mathrm{mM} ;(7)[\mathrm{SDS}]=11 \mathrm{mM}$.

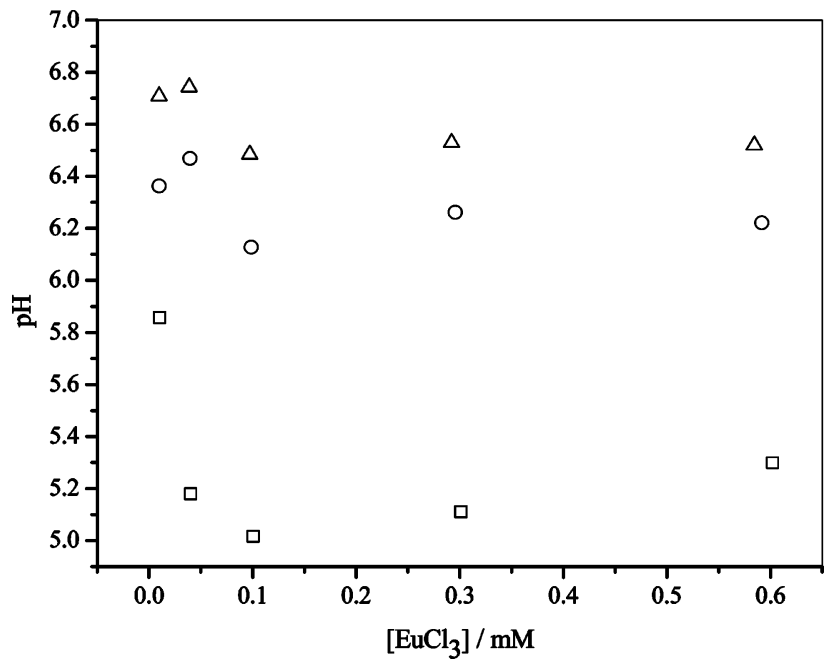

Figure 7. Dependence of $\mathrm{pH}$ on $\mathrm{EuCl}_{3}$ addition in aqueous solutions without $(\square)$ and with SDS: $(\bigcirc) 7 \mathrm{mM},(\triangle) 12 \mathrm{mM}$.

indication about the association stoichiometry between $\mathrm{Eu}(\mathrm{III})$ and $\mathrm{DS}^{-}$. It is possible to observe that, upon increasing $\left[\mathrm{EuCl}_{3}\right]$, the binding ratio, $\beta$, decreases following an exponential function, from a value around 20 to a value to approximately 4 . Comparing the binding ratios with the results of turbidimetric analysis, we can conclude that the decrease of the binding ratio value is accompanied by an increase of light scattering. These values 
Table 1. Effect of Temperature and Initial Concentration of $\mathbf{E u C l}_{3}$ on the Maximum Interaction Concentration (mic) and Binding Ratio $(\beta)$ of $\mathrm{SDS} / \mathrm{EuCl}_{3}$ Aggregates $^{a}$

\begin{tabular}{|c|c|c|c|c|c|c|c|c|c|c|c|}
\hline \multicolumn{4}{|c|}{$25^{\circ} \mathrm{C}$} & \multicolumn{4}{|c|}{$30^{\circ} \mathrm{C}$} & \multicolumn{4}{|c|}{$40^{\circ} \mathrm{C}$} \\
\hline$\left[\mathrm{EuCl}_{3}\right] / \mathrm{mM}$ & $\mathrm{mic} / \mathrm{mM}$ & $\beta$ & $\mathrm{cac}_{2} / \mathrm{mM}$ & {$\left[\mathrm{EuCl}_{3}\right] / \mathrm{mM}$} & $\mathrm{mic} / \mathrm{mM}$ & $\beta$ & $\mathrm{cac}_{2} / \mathrm{mM}$ & {$\left[\mathrm{EuCl}_{3}\right] / \mathrm{mM}$} & $\mathrm{mic} / \mathrm{mM}$ & $\beta$ & $\mathrm{cac}_{2} / \mathrm{mM}$ \\
\hline 0.0794 & 1.69 & $21(4$ & $6.87(0.35)$ & 0.0797 & $0.37)$ & 20 & $7.46(0.36)$ & 95 & $1.74(0.13)$ & $22(2)$ & 7.0 \\
\hline 0.0993 & $1.66(0.20)$ & $17(2)$ & 6.98 & .0994 & $1.65(0.22)$ & $17(2)$ & 7.40 & & $1.84(0.27)$ & $19(3)$ & 6.95 \\
\hline 0.1982 & $1.81(0.12)$ & $9.1(0.6)$ & $7.08(0.13)$ & 0.1988 & $1.79(0.10)$ & $9.0(0.5)$ & $7.56(0.10)$ & & $1.87(0.12)$ & $9.5(0.6)$ & $7.16(0.12)$ \\
\hline 0.2973 & $1.85(0.08)$ & $6.2(0.3)$ & $7.26(0.09)$ & 0.2976 & $1.92(0.07)$ & $6.4(0.2)$ & $7.66(0.08)$ & 0.2954 & $1.99(0.10)$ & $6.7(0.3)$ & $7.24(0.11)$ \\
\hline 0.3956 & $2.06(0.08)$ & $5.2(0.2)$ & $7.22(0.09)$ & 0.3960 & $2.11(0.05)$ & $5.3(0.1)$ & $7.67(0.07)$ & 0.3930 & $2.12(0.05)$ & $5.4(0.1)$ & $7.35(0.07)$ \\
\hline 0.5922 & $2.40(0.05)$ & $4.0(0.1)$ & $7.26(0.08)$ & 0.5917 & $2.45(0.04)$ & $4.2(0.1)$ & $7.72(0.08)$ & 0.5873 & $2.46(0.04)$ & $4.2(0.1)$ & $7.32(0.08)$ \\
\hline
\end{tabular}

${ }^{a}$ The values inside parentheses are standard deviations of average values.

suggest that probably the shape of the aggregate will change with increasing $\left[\mathrm{EuCl}_{3}\right]$, from a sphere to a cylindrical shape. This is in agreement with observations on the behavior of SDS in the presence of aluminum(III). ${ }^{8,11,12}$ As discussed before, the $\mathrm{cmc}^{\text {ap }}$ is higher than the SDS cmc. Comparison with the behavior of aluminum(III) suggests that this may correspond to the change from spherical to cylindrical aggregates; however, the $\mathrm{cmc}^{\mathrm{ap}}$ values can be corrected by taking into account the surfactant concentration necessary for complete association with all europium chloride present in solution. That is, the $\mathrm{cac}_{2}\left(=\mathrm{cmc}^{\text {ap }}\right.$ $-[\mathrm{SDS}]_{\mathrm{mic}}$ ) can be calculated and shown in Table 1 . The values of the $\mathrm{cac}_{2}$ are lower than the cmc of SDS, showing that the onset of SDS micellization responds to added electrolyte, which is in agreement with the literature. ${ }^{45}$ With analysis of the effect of $\mathrm{EuCl}_{3}$ on the $\mathrm{cac}_{2}$, it is possible to check that a small increase of the $\mathrm{cac}_{2}$ with an increase of Eu(III) occurs, but such an increase can be neglected on the basis of the experimental error. This is in agreement with the previous assumption that all $\mathrm{EuCl}_{3}$ is consumed to form aggregates with SDS. For this reason, the average $\mathrm{cac}_{2}$ values at 25,30 , and $40^{\circ} \mathrm{C}$ were calculated and are equal to $7.11( \pm 0.25), 7.58( \pm 0.21)$, and $7.18( \pm 0.13) \mathrm{mM}$, respectively. The alteration in standard Gibbs energy of the micelles due to the presence of $\mathrm{Eu}(\mathrm{III})$, or $\mathrm{Eu}(\mathrm{III})$ aggregates, in solution is given by the equation $\Delta G_{\mathrm{m}}^{\circ}=R T \ln \left(\mathrm{cac}_{2} / \mathrm{cmc}\right)$, where $\mathrm{cmc}$ is the critical micelle concentration. From this equation, $\Delta G^{\circ}{ }_{\mathrm{m}}$ values of $-383( \pm 88),-267( \pm 71)$, and $-527( \pm 48)$ $\mathrm{J} / \mathrm{mol}$, at 25,30 , and $40{ }^{\circ} \mathrm{C}$, respectively, were calculated. Even when the experimental error is taken into account, it is still possible to observe a slight negative trend of $\Delta G_{\mathrm{m}}^{\circ}$ values with increasing temperature. These results indicate that the SDS micelle stabilization, in the presence of $\mathrm{Eu}(\mathrm{III}) / \mathrm{DS}^{-}$aggregates, tends to be more pronounced at higher temperatures (i.e., in this case micellization is temperature-induced). Two major competing parameters may influence SDS micelle formation in the presence of europium(III) salts: temperature and ionic strength (due to the presence of $\mathrm{Eu}(\mathrm{III}) / \mathrm{DS}^{-}$aggregates and their counterions). ${ }^{46}$ Since the cmc normally depends very little on temperature, ${ }^{47}$ the predominant effect seems to be the high ionic strength due to the trivalent cation. In contrast, an increase of temperature would tend to disturb the aggregate packing and, consequently, lead to an increase of counterions in solution. In conclusion, an increase of temperature may tend to have a synergistic effect on the ionic strength, which may justify the decrease of $\Delta G^{\circ}$ m with an increase of temperature.

(45) Griffihs, P. C.; Roe, J. A.; Bales, B. L.; Pitt, A. R.; Howe, A. M. Langmuir 2000, 16, 8248-8254. 18.

\section{Conclusions}

Conductometric analysis is shown to be a reliable technique to study the interactions between europium chloride and sodium dodecyl sulfate in aqueous solution. For Eu(III) concentrations below $0.08 \mathrm{mM}$ and for [SDS] above $0.08 \mathrm{mM}$, two different aggregates were detected. At low SDS concentrations, the formation of $\mathrm{Eu}(\mathrm{III})$ and $\mathrm{DS}^{-}$micelles was indicated and confirmed by fluorescence analysis, with a critical micelle concentration for europium(III) dodecyl sulfate of $0.65 \mathrm{mM}$. From the similarity of chemical behavior of the trivalent lanthanide ions, the cmc values of the other lanthanide (III) dodecyl sulfates are expected to lie in the same concentration range. From theoretical models of micellization of ionic surfactants, ${ }^{48,49}$ electrostatic effects are likely to play a major role in aggregation in these systems, and the surface charge density of the micelles ${ }^{37}$ will be a determining factor both in the type and size of aggregates produced. However, there is also increasing evidence of the importance of loss of counterion hydration water molecules on formation of surfactant micellar or reversed micellar aggregates, ${ }^{24,50,51}$ leading to complexation between surfactant and counterion, and it is possible that such dehydration effects may also have an influence on the binding in this case. The binding ratio, $\mathrm{SDS}: \mathrm{EuCl}_{3}$, is dependent on $\mathrm{EuCl}_{3}$ initial concentration, changing from 20 to around 5-4 when $\left[\mathrm{EuCl}_{3}\right]$ increases. Such a change can be justified by an alteration of the aggregate shape. At high concentrations, formation of cylindrical aggregates is suggested, in agreement with reports on the behavior of aluminum dodecyl sulfates. ${ }^{8,11,12}$ However, the $\mathrm{pH}$ dependence in the presence of europium(III) appears to be somewhat different from and less significant than that with aluminum(III), probably due to the smaller degree of hydrolysis of the lanthanide ion. ${ }^{41}$ Because of this, it should be possible to design lanthanide/aluminum systems using SDS as surfactant templates for the preparation of Eu containing mesosopic or mesoporous materials based simply on the behavior of the aluminum(III) SDS system. Studies on this are in progress.

Acknowledgment. We are grateful for financial support from POCTI/FCT/FEDER.

\section{LA060285E}

(47) Benrraou, M.; Bales, B. L.; Zana, R. J. Phys. Chem. B 2003, 107, 1343213440.

(48) Hall, D. G. J. Chem. Soc., Faraday Trans. 1 1981, 77, 1121-1156. (49) Gunarsson, G.; Jönsson, B.; Wennerström, H. J. Phys. Chem. 1980, 84, $3114-3121$.

(50) Geng, Y.; Romsted, L. S.; Menger, F. J. Am. Chem. Soc. 2006, 128, $492-501$.

(51) Faeder, J.; Albert, M. V.; Ladanyi, B. M. Langmuir 2003, 19, 2514- 